\title{
ENTRE A GORDURA E O BISTURI: ESTRATÉGIAS BIOPOLÍTICAS EM DISCURSOS SOBRE A CIRURGIA BARIÁTRICA
}

\section{BETWEEN OBESITY AND SCAPEL: BIOPOLITICAL STRATEGIES IN DISCOURSE ABOUT BARIATRIC SURGERY}

Francisco Vieira da Silva

Claudemir Sousa

Dentro de todo gordo há um magro debatendo-se desesperadamente para sair.

(Cyril Connoly)

Năo posso parar de pensar naquele traseiro branco e gordo

Penso em apalpá-lo

Penso em aplaudi-lo

Mas mulheres gordas nâo sâo saudáveis

Melhor comê-la escondido

(Letícia Brito)

\begin{abstract}
RESUMO: O artigo analisa materialidades discursivas que enunciam acerca da cirurgia bariátrica (gastroplastia), com o intento de investigar o funcionamento de estratégias biopolíticas que normalizam o corpo obeso, inserindo-o no âmbito de uma moral da saúde e do bem-estar. Para isso, tomamos como principal aparato teórico as reflexóes de Michel Foucault acerca do biopoder e da biopolítica. Do ponto de vista metodológico, trata-se de um estudo de cunho descritivo-interpretativo, cuja abordagem é qualitativa. O corpus é formado por materialidades que circularam na web (Revista Veja Online, HuffPost Brasil, Bariátricos e YouTube). As análises denotam que, nas materialidades estudadas, funcionam estratégias biopolíticas as quais consideram a gastroplastia como uma alternativa eficaz e necessária na produçâo da qualidade de vida dos sujeitos obesos.
\end{abstract}

PALAVRAS-CHAVE: Biopolítica. Bariátrica. Discurso

ABSTRACT: The article analyses discursive materialities that state about bariatric surgery (gastroplasty), with the aim of investigating the functioning of the biopolitical strategies that normalize the obese body, inserting it within 
the framework of a moral of health and well-being. For this, we take as our mainly theoretical reference Michel Foucault's reflections about the biopower and biopolitics. From the methodological point of view, this is a descriptiveinterpretative study, whose approach is qualitative. The corpus is composed by materialities that circulated on the web (Veja Magazine Online, HuffPost Brazil, Bariátricos and YouTube). The analysis show that, in the materialities studied, biopolitical strategies work, which consider gastroplasty as an effective and necessary alternative in the production of life quality of obese subjects.

KEYWORDS: Biopolitics. Bariatric. Discourse.

\section{INTRODUÇÃO}

Iniciamos este escrito relatando um episódio trivial, mas pertinente para as reflexóes a serem desenroladas aqui. No dia seis de maio de 2018, o programa Domingáo do Faustăo, exibido aos domingos pela Rede Globo de Televisâo, recebeu, dentre as várias atraçōes, a banda Fat Family, um conjunto musical brasileiro formado por seis irmáos que estourou no final dos anos de 1990. Inspirados na música norte-americana de matriz negra e nos grupos vocais de estilo gospel, os irmáos chamavam a atençáo pelo peso elevado que exibiam, ficando expresso no título da banda ("família gorda"). Todavia, no âmbito da apresentaçâo na atraçăo comandada por Fausto Silva, observaram-se mudanças substanciais nos corpos dos integrantes do Fat Family, agora bem mais magros que outrora. Ao mostrar um vídeo do conjunto no início da carreira e constatar a transformaçăo corporal, Faustăo disparou "Viva o milagre da bariátrica!"1. Passado o fato, indagamos num primeiro instante: o nome do grupo ainda condiz com o estatuto corporal dos seus integrantes? Depois, de maneira mais ampla, interrogamos: em que medida essas transformaçóes corporais intervêm na produçáo da subjetividade? O que a realizaçăo da bariátrica diz daquilo que somos e que estamos nos tornando na relaçăo com os nossos corpos?

Ultimamente, o número de gastroplastias, popularmente conhecidas como cirurgias bariátricas, tem crescido de maneira exponencial no país, de modo que o Brasil ocupa o segundo lugar em todo o mundo na realizaçáo desse tipo de procedimento, perdendo apenas para os Estados Unidos. Trata-se de um tratamento indicado a pacientes com graves índices de obesidade e consiste numa intervençăo que reduz consideravelmente a extensâo do estômago, com vistas a modificar o trajeto dos alimentos no aparelho digestivo e refrear a sua absorçấo ${ }^{2}$. Baseia-se em critérios como o Índice de Massa Coporal (ICM), a idade e as doenças associadas à obesidade. De acordo com a Sociedade Brasileira de Cirurgia Bariátrica e Metabólica (SBCBM), o crescimento das referidas cirurgias elevou-se em torno de 39\%. Em 2012, foram realizados cerca de 70 mil procedimentos e, em 2016, a cifra subiu para 100 mil $^{3}$. É possível cogitar que

1 Vale frisar que o próprio apresentador também se valeu do procedimento cirúrgico da bariátrica, com vistas a perder peso.

2 Disponível em: https://claudia.abril.com.br/saude/cirurgia-bariatrica-especialistas-duvidas-posoperatorio/. Acesso em: 01 maio. 2018.

3 Disponível em: http://www1.folha.uol.com.br/equilibrioesaude/2017/08/1908949-cirurgia-bariatrica- 
esse avanço caminha lado a lado com o aumento vertiginoso da obesidade no Brasil, dado que, em dez anos, o crescimento da obesidade ocorreu em todas as faixas etárias e quase dobrou em jovens de 18 a 24 anos $^{4}$. Estima-se que cerca de um em quatro brasileiros encontra-se em situaçăo de obesidade, de modo que se intensifica o debate em torno dessa questăo nas diferentes instâncias da sociedade, principalmente do ponto de vista das políticas públicas de saúde.

A ampliaçâo das ocorrências das bariátricas conecta-se com o fenômeno da patologizaçâo da obesidade em todo o mundo, tornando-se um flajelo planetário, nos dizeres de Vigarello (2012). Nessa lógica, Costa (2015, p.44-45) esclarece que: "Tal enfermidade se transformou em uma questăo política: uma doença que consome todos os esforços individuais e os investimentos coletivos em aparatos de assistência primários, como programas de saúde da família, ou complexos, como hospitais e cirurgias". Considerando, pois, que a popularizaçâo das cirurgias bariátricas corresponde a uma urgência história, o aumento no número de obesos e a preocupaçăo em estancar a epidemia, é necessário pensarmos, a partir de um viés foucaultiano, acerca da emergência dos discursos acerca desse procedimento cirúrgico hoje e dos modos através dos quais os sujeitos contemporâneos relacionam-se com seus corpos, especialmente quando estes se encontram à margem da norma da saúde e do bem-estar.

Ao tornar-se uma questâo de saúde coletiva, a obesidade entra no domínio dos cálculos e da administraçâo política. Refletimos, nesse aspecto, a partir das teorizaçóes de Michel Foucault a respeito do biopoder e da biopolítica. Nas abordagens desse autor, o biopoder é compreendido como um tipo de poder que tem como alvo a vida biológica e a biopolítica refere-se a uma série de medidas racionalizadas que surgem em meados do século XVIII e se voltam para o governo dos seres viventes. Dessa maneira, situamos a emergência dos discursos acerca da cirurgia bariátrica como um elemento do biopoder e como uma das estratégias biopolíticas, as quais visam garantir o bem-estar e a saúde dos sujeitos obesos, assegurando o controle e a gestăo da vida dessa parcela da população.

Em suma, as discussóes desenvolvidas neste escrito permitem-nos radiografar a produçăo de subjetividade e os efeitos dos dispositivos de saber- poder no funcionamento de verdades acerca do corpo. Situando nosso horizonte investigativo nos limites da web, deparamo-nos com uma vastidâo de materialidades discursivas que tratam da questăo da gastroplastia, tais como: postagens nas mais variadas páginas e perfis em redes de interconexâo social, notícias em sites informativos e em blogs, artigos científicos publicados em periódicos ou em anais de eventos, vídeos de especialistas na área da saúde discutindo a cirurgia e de depoimentos de sujeitos que já passaram pela bariátrica ou que ainda esperam pelo procedimento em plataformas como o YouTube. Há ainda uma diversidade de grupos em redes sociais que reúnem sujeitos em processo de recuperaçâo, interessados em serem operados e outros que já fizeram a intervençâo.

Esse arquivo da/na mídia digital atesta a premência da questăo na atualidade, o que pode ser percebida também na irrupçăo de reflexóes acadêmicas em torno do tema. A

cresce-no-pais-e-pode-incluir-ainda-mais-pacientes.shtml. Acesso em: 01 maio 2018.

4 Disponível em: http://www1.folha.uol.com.br/equilibrioesaude/2017/08/1908212-obesidade-disparaentre-jovens-do-pais.shtml. Acesso em: 01 maio 2018. 
despeito de os estudos acerca dos efeitos da bariátrica, no seio das ciências da saúde (MARCHESINI; ANTUNES, 2017, DE-MARCHI et al, 2017; SILVA; FARO, 2015; BARROSO et al, 2017) sejam efervescentes, pouco se observa reflexóes semelhantes noutros campos do saber ${ }^{5}$. Nesse sentido, o presente estudo, ao pensar os dizeres sobre a cirurgia bariátrica em variadas materialidades da rede digital, no âmbito da Análise do Discurso de orientaçăo foucaultiana, acaba por se configurar numa proposta que pode contribuir de maneira profícua em relaçâo ao debate que circunda a cirurgia bariátrica, especialmente se considerarmos o nosso lugar investigativo, haja vista que esse tema, conforme frisamos, tende a se circunscrever na área da saúde. Entendendo que o saber médico perpassa basicamente a totalidade das produçôes discursivas acerca da gastroplastia, acreditamos que nossa abordagem pode mostrar o funcionamento das estratégias discursivas que margeiam essa produçấo enunciativa no campo da saúde e para além deste.

O objetivo deste estudo consiste em analisar dizeres acerca da cirurgia bariátrica em materialidades discursivas da web, com o propósito de investigar o funcionamento de estratégias biopolíticas que procuram assegurar saúde e bem-estar aos sujeitos com índices elevados de obesidade. Compreendemos que tais estratégias năo estâo situadas somente na visada das políticas estatais, haja vista que a obesidade "[...] passou a ser uma ameaça sanitária, uma epidemia que se alastra, rastejante e dissimulada [...]" (VIGARELLO, 2012, p. 321), de maneira a suscitar esforços provenientes dos mais diversos setores da sociedade. Embora as materialidades a serem estudadas aqui apresentem variados posicionamentos discursivos, convém pontuar, por outro lado, que tais discursos partem de um ponto em comum: a predominância do saber médico na produçấo de verdades acerca do sujeito obeso.

O corpus de análise é constituído por materialidades discursivas presentes na mídia digital, quais sejam: a) uma matéria do da revista Veja intitulada Cientistas de Havard recomendam bariátrica para adolescentes obesos (2018)6; b) um texto opinativo que circulou no site do Huffpost Brasil (5 motivos para afirmar: emagrecer com cirurgia bariátrica nâo é fácil $)^{7}$; c) dois depoimentos de sujeitos que realizaram a gastroplastia, os quais estâo disponíveis no site Bariátricos ${ }^{8}$ e d) dois vídeos de uma campanha realizada pela Sociedade Brasileira de Cirurgia Bariátrica e Metabólica (SBCBM), disponíveis no YouTube ${ }^{9}$. A seleçáo desse material deu-se em virtude dos seguintes critérios: a) as materialidades deveriam estar disponíveis na mídia digital; $b$ ) precisariam ter sido veiculadas pelo menos nos últimos quatro anos; c) necessitariam ser materialidades corporificadas em gêneros discursivos variados. No que tange à metodologia, este estudo segue um viés descritivo-interpretativo numa abordagem prioritariamente qualitativa.

5 Uma exceçâo é o estudo de Costa (2015), cujo foco incide sobre os discursos de sujeitos que realizaram a cirurgia bariátrica em blogs voltados diretamente a essa temática, a partir da biopolítica e das reinvençōes dessas tecnologias de poder nas tecnologias digitais.

6 Disponível em: https://veja.abril.com.br/saude/cientistas-de-harvard-recomendam-bariatricapara-adolescentes-obesos/. Acesso em: 03 maio 2018.

7 Disponível em: https://www.huffpostbrasil.com/anna-carolina-lementy/5-motivos-paraafirmar-emagrecer-com-cirurgia-bariatrica-nao-e a 21695854/. Acesso em: 03 maio 2018.

8 Disponível em: http://www.bariatricos.com.br/depoimentos/. Acesso em: 04 maio 2018.

9 Disponíveis em: https://www.youtube.com/watch?v= cPQ932mUm4 e em: https://www.youtube.com/ watch? $=\mathrm{kPi3Sy} 9 \mathrm{TCr} 4$. Acesso em: 03 maio de 2018. 
Para tanto, este texto encontra-se organizado nos seguintes moldes. Na seçăo seguinte, discutiremos alguns conceitos da obra foucaultiana, tais como discurso, enunciado, biopoder e biopolítica. Posteriormente, delinearemos as análises do corpus e, em seguida, esboçam-se algumas observaçôes de feiçôes conclusivas a essa investigaçăo.

\section{BIOPOLÍTICA E BIOPODER: O DESENVOLVIMENTO DO DISPOSITIVO DE NORMALIZAÇÃO DO CORPO}

Uma questâo que se formularia para verificar a pertinência da realizaçâo deste trabalho seria: o que fez com que o corpo se tornasse objeto de estudos hoje? Talvez, a resposta para isso venha das formulaçóes de Foucault, que apreende o nascimento de uma biopolítica dos corpos em uma longa duraçăo histórica, cujas condiçóes de possibilidade foram acontecimentos de variadas ordens. De acordo com Duarte (2008, p. 47, grifos do autor): "[...] os conceitos de biopoder e de biopolítica surgem na reflexăo foucaultiana como o ponto terminal de sua genealogia dos micropoderes disciplinares, iniciada nos anos de 1970".

Essa discussāo é situada por Foucault nas transformaçôes do mecanismo de poder existente na sociedade de soberania, em que prevalecia um direito do rei de decidir sobre a vida e a morte dos seus súditos. Esse direito era exercido de maneira indireta, nos casos em que sua própria existência estivesse ameaçada, tais como o caso da guerra, devendo o Estado ser defendido, ou de forma direta, como no caso em que o súdito infringisse as leis do soberano, devendo aquele ser morto como castigo. Assim, Foucault (1988) considera que o direito do soberano sobre a vida só se exercia com o direito de matar, ou seja, "o direito que é formulado como de vida e morte é, de fato, o direito de causar a morte ou de deixar viver" (FOUCAULT, 1988, p. 128, grifos do autor), visto que, naquela sociedade, o mecanismo de poder se exercia como forma de subtraçáo do sangue, de apreensăo do corpo e da vida para suprimi-la. Na época clássica, esse mecanismo de poder sofreu transformaçăo no ocidente, ganhando outras funçōes, como a de controle, vigilância, organizaçâo, produçâo e funcionamento das forças, em vez de sua destruiçáo. Com isso, o direito de matar dá lugar a um direito de viver, do qual a morte aparece como um reverso. Dessa forma, Foucault (1988) considera que se passou de uma existência jurídica do soberano para uma existência biológica da populaçấo.

Dessa maneira, tudo aquilo que significa morte passa a ser vergonhoso para uma sociedade em que o poder assumiu a funçâo de gerir a vida, tornando-se legítima apenas a morte daqueles que representam um perigo biológico para os outros. A morte era vista como a passagem da soberania terrestre para outra mais poderosa. Essa passagem era acompanhada por um cerimonial político. Na nova ordem, é sobre a vida que se fixa o poder.

Assim, Foucault (1988) situa no século XVIII o desenvolvimento do poder sobre a vida, em duas formas interligadas por um feixe de relaçôes: o primeiro, centrado no corpo-máquina, que deveria ser adestrado, ter suas aptidōes ampliadas, suas forças subtraídas, tornado dócil e útil, e ser integrado em sistemas de controle eficazes e econômicos por intermédio das "disciplinas: anátomo-política do corpo humano" (FOUCAULT, 1988, p. 31, grifos do autor). 
Já o segundo, formado na metade do século XVIII, realizou-se sobre o corpo-espécie, como suporte de processos biológicos, em torno da proliferaçăo da populaçăo, dos nascimentos, da mortalidade, do nível de saúde, da duraçăo da vida, da longevidade, mediante intervençôes e controles, que o autor caracteriza como uma "bio-política da populaçâo" (FOUCAULT, 1988, p. 31, grifos do autor).

Dessa maneira, o poder sobre a vida perpassa os mecanismos disciplinares do corpo e de regulaçóes populacional, possuindo uma face anatômica, voltada para os desempenhos do corpo, e outra biológica, que encara os processos da vida da espécie. Com essa nova forma de poder, desenvolvem-se técnicas diversas de gestăo e controle das populaçóes, como as observaçóes econômicas, dos problemas de natalidade, longevidade, saúde pública, habitaçăo e migraçăo. Abre-se, diz Foucault (1988, p. 132) "a era do "bio-poder"'.

Foucault (1988) considera que o biopoder foi um elemento indispensável para o desenvolvimento do capitalismo, pois sua garantia dependeu da inserçâo controlada dos corpos no aparelho de produçâo e do ajustamento da populaçấo aos processos econômicos. Além disso, os fenômenos próprios à vida humana passaram a ser integrados no saber e no poder, no campo das técnicas políticas.

Com isso, proliferam tecnologias políticas que investem sobre o corpo, a saúde, as maneiras de se alimentar e de morar, as condiçôes de vida, etc., que dăo lugar a vigilâncias, controles, ordenaçóes, exames médicos ou psicológicos, a micropoderes sobre o corpo e também a medidas maciças, estimativas estatísticas, intervençóes que visam a toda a populaçáo. Em resumo, uma forma de acesso à vida do corpo e da espécie.

A biopolítica representa, assim, a tomado do homem enquanto ser vivo como objeto de poder. Uma estatizaçăo do biológico, realizada pelo mecanismo de biopoder. A biopolítica da espécie humana lança mâo da mediçâo estatística como forma de produzir um saber sobre os alvos de controle do biopoder. Será necessário tratar as doenças, porquanto subtraem a força e diminuem o tempo de trabalho, causando custos na economia, já que necessitam de tratamento. Com isso, introduz-se uma medicina que terá como funçăo a higiene pública, através de campanhas de aprendizado e medicaçaáo da populaçâo. O biopoder possui funçáo de disciplina e regulamentaçăo da espécie, visando aumentar a vida, controlar acidentes, eventualidades, deficiências e a própria morte, que só aparece em estatísticas.

Conforme esclarece Candiotto (2013), diferentemente da crueldade dos estados totalitários, num Estado de Bem-estar Social (Welfare State), a tônica é fazer viver, tendo como base em açôes de seguridade social que atravessam toda a existência de um indivíduo. Para Candiotto (2013), isso começa na infância, por meio de políticas de inclusâo educacionais e nutricionais; posteriormente serăo implementadas políticas de empregabilidade, de qualificaçăo profissional, de segurança do trabalho, bem como de previdência e benefícios trabalhistas. Juntem-se a isso as garantias de "acesso à moradia, o lazer e à cultura" (CANDIOTTO, 2013, p. 91), os planos de saúde e a manutençâo dos padrôes de vida e de consumo dos indivíduos. Entendemos que as políticas de saúde e assistência à preservaçăo da vida perpassam toda a vida do sujeito, desde as especificidades da infância, passando pelas idiossincrasias da adolescência e da vida adulta até chegar às recentes descobertas das potencialidades da velhice. 
Entre a disciplina e a regulamentaçăo, afirma Foucault (1999), circula a norma. Por isso, ele fala que vivemos em uma sociedade de normalizaçăo, na qual a medicina é um mecanismo de saber-poder, uma técnica de intervençâo que tem funçăo normalizadora, pois seu poder disciplinar individualizantes sobre o corpo orgânico e biológico tem efeito regulamentar sobre a populaçăo. Conforme mostraremos em nossas análises, o saber da medicina perpassa praticamente a totalidade das produçóes discursivas acerca do sujeito obeso.

Quanto ao termo poder, utilizado pelo autor para se referir a esse mecanismo que estimula a produçâo da vida, é necessário compreendê-lo como:

multiplicidade de correlaçóes de forças imanentes ao domínio onde se exercem e constitutivas de sua organizaçăo; o jogo que, através de lutas e afrontamentos incessantes as transforma, reforça, inverte; os apoios que tais correlaçóes de força encontram umas nas outras, formando cadeias ou sistemas ou ao contrário, as defasagens e contradiçōes que as isolam entre si; enfim, as estratégias em que se originam e cujo esboço geral ou cristalizaçăo institucional toma corpo nos aparelhos estatais, na formulaçáo da lei, nas hegemonias sociais (FOUCAULT, 1988, p. 88-89).

O poder, nesta concepçăo, está em toda parte, pois é produzido constantemente, em todas as relaçóes. Ele "năo é uma instituiçăo e nem uma estrutura, nâo é uma certa potência de que alguns sejam dotados: é o nome dado a uma certa situaçăo estratégica complexa numa sociedade determinada" (FOUCAULT, 1988, p. 89). Ele năo é adquirido, compartilhado e guardado. É exercido em diversos pontos de modo desigual.

Por isso, Foucault (1988, p. 91) considera que "lá onde há poder há resistência e, no entanto (ou melhor, por isso mesmo) esta nunca se encontra em posiçăo de exterioridade em relaçăo ao poder". As relaçôes de poder existem em funçăo de uma multiplicidade de pontos de resistência, que fazem o papel de seu adversário e alvo. Elas estăo em toda rede de poder, existindo resistências possíveis e necessárias.

Ao compreender o poder como um modo de açăo de uns sobre outros, que nâo é consentido em renuncia à liberdade, Foucault (2009) considera que o poder só se exerce sobre sujeitos livres e o correlaciona ao termo governo, que possui uma relaçấo com os dispositivos de segurança e populaçăo. Na compreensăo de Foucault (2013a), governar é uma prática múltipla, exercida, por exemplo, pelo pai de família, pelo pedagogo, pelo professor, pelo governador de Estado, e, acrescentamos, pela mídia, por intermédios de seus enunciados.

A finalidade do governo é dispor as coisas de um modo correto para conduzi-las a um objetivo adequado a cada coisa a governar. Foucault (2013a) afirma que, durante o século XVI e até o século XVIII, a arte de governar esteve limitada à forma de soberania e apoiada no modelo de família. Com a expansâo demográfica no século XVII, em que emerge o problema da populaçáo, a noçâo da economia será centrada em outra coisa que năo mais a família. É a estatística, consoante Foucault (2013a, p. 324), que vai revelar as características próprias da populaçăo e os fenômenos que năo se reduzem à família: o numero de mortos, de doentes, regularidade de acidentes, etc.

O objetivo final do governo passa a ser a populaçăo, cuja saúde, riqueza e duraçăo de vida devem aumentar. Para atingir isso, deve-se usar como instrumentos: 
Campanhas, através das quais se age diretamente sobre a populaçăo, e técnicas que văo agir indiretamente sobre ela e que permitirăo aumentar, sem que as pessoas se deem conta, a taxa de natalidade, ou dirigir para uma determinada regiăo ou para uma determinada atividade os fluxos da populaçấo (FOUCAULT, 2013a, p. 425).

Ao se construir um conjunto de saberes acerca dos fenômenos referentes à populaçăo, ocorre, segundo Foucault (2013a), a passagem de uma arte de governar da soberania um regime dominado pelas técnicas de governo em que a populaçâo é o alvo principal e cujos mecanismos essenciais sâo os dispositivos de segurança. Vivemos, desde o século XVIII, na era da governamentalidade, entendida como:

1) o conjunto constituído pelas instituiçōes, procedimentos, análises e reflexōes, cálculos e táticas que permitem exercer esta forma bastante específica e complexa de poder, que tem por alvo a populaçăo, por forma principal de saber a economia política e por instrumentos técnicos essenciais os dispositivos de segurança.

2) a tendência que em todo Ocidente conduziu incessantemente, durante muito tempo, à preeminência deste tipo de poder, que se pode chamar de governo, sobre todos os outros - soberania, disciplina etc. - e levou ao desenvolvimento de uma série de aparelhos específicos de governo e de um conjunto de saberes.

3) o resultado do processo através do qual o Estado de justiça da Idade Média, que se tornou nos séculos XV e XVI Estado administrativo, foi pouco a poço governamentalizado. (FOUCAULT, 2013a, p. 429).

Conforme discutiremos em nossas análises, a obesidade, ao ser patologizada, se tornou em uma questăo política. O seu combate, que em alguns casos ocorre pela realizaçâo da cirurgia bariátrica, é, hoje, uma urgência histórica e, como tal, demanda respostas por parte do governo populacional, que vem em forma de discursos provenientes da área da saúde, incentivando os sujeitos a cuidarem de seus corpos.

Foucault (2013b) compreende o dispositivo a partir de três formulaçóes, a saber:

em primeiro lugar, um conjunto decididamente heterogêneo que engloba discursos, instituiçōes, organizaçōes arquitetônicas, decisōes regulamentares, leis, medidas administrativas, enunciados científicos, proposiçōes filosóficas, morais, filantrópicas. Em suma, o dito e o năo dito săo os elementos do dispositivo. 0 dispositivo é a rede que se pode estabelecer entre estes elementos (FOUCAULT, 2013b, p. 364).

Em segundo lugar, ele trata da natureza da relaçâo entre os elementos do dispositivo. Entre eles, existe um tipo de jogo, de mudança de posiçôes, modificaçâo de funçôes. Com isso, o discurso pode aparecer como um programa de uma instituiçâo ou como algo que permite justificar e mascarar uma prática ou uma reinterpretaçáo dessa prática.

Já em terceiro lugar, essa noçâo é compreendida como "um tipo de formaçâo que, em um determinado momento histórico, teve como funçăo principal responder a uma urgência. O dispositivo tem, portanto, uma funçăo estratégica dominante" (FOUCAULT, 2013b, p. 365). Temos, assim, um dispositivo de saúde, que tem como seu principal elemento o corpo obeso de um sujeito que é estimulado a cuidar de si. Esse cuidado implica em um conjunto de ocupaçóes dedicado a voltar-se para si (FOUCAULT, 2005), a partir de uma ortopedia moral que propugna o corpo magro como aquilo que se deseja e, em contrapartida, a obesidade como algo que deve ser evitado e eliminado. 


\section{ESTRATÉGIAS BIOPOLÍTICAS EM DISCURSOS SOBRE A CIRURGIA BARIÁTRICA}

O corpus de análise é formado pelas materialidades especificadas na introduçāo deste escrito. Iniciamos nossa investigaçăo pela reportagem que circulou no site da revista Veja. A materialidade em questăo discursiviza um estudo realizado pela Universidade de Havard que trata da indicaçăo do procedimento cirúrgico para o tratamento da obesidade entre os adolescentes. Eis alguns excertos da reportagem:

Cientistas de Harvard recomendam bariátrica para adolescentes obesos

De acordo com um novo estudo apresentado apenas uma pequena parte dos adolescentes obesos realizam a cirurgia, embora seja a melhor opçáo em longo prazo

Pesquisadores de Harvard defendem o uso da cirurgia bariátrica, que reduz o estômago para diminuir o peso de indivíduos obesos, como alternativa à obesidade infantil. De acordo com um estudo apresentado na segunda-feira durante a ENDO 2018, uma conferência anual de endocrinologistas, que aconteceu em Chicago, nos Estados Unidos, apenas uma pequena parcela dos adolescentes e jovens adultos que sofrem com a doença sâo submetidos à cirurgia, apesar de ela ser considerada o tratamento a longo prazo mais eficaz para a perda de peso.

[...]"A obesidade entre adolescentes e jovens está crescendo rapidamente. No entanto, a cirurgia de reduçăo de peso nâo é muito utilizada em grupos dessa faixa etária", disse em nota a médica Karen Campoverde-Reyes, uma das colaboradoras do estudo e pesquisadora da Escola de Medicina de Harvard e do Hospital Geral de Massachussetts.

[...]as taxas de cirurgias bariátricas estabilizaram nos últimos anos, ainda que a obesidade tenha aumentado nâo apenas nos EUA, mas no mundo inteiro. Essa é uma preocupaçâo particular entre especialistas porque crianças com excesso de peso ou obesidade têm uma probabilidade cinco vezes maior de se tornarem adultos com obesidade ou excesso de peso, em comparaçăo com aquelas com peso normal.

[...] Atualmente, o CDC recomenda que famílias, médicos e escolas ajudem as crianças a evitarem ou enfrentarem a obesidade através de dietas saudáveis, bons hábitos de sono e exercícios regulares. Mas, para os pesquisadores, ainda é necessário educar médicos, residentes, assistentes sociais e enfermeiras escolares para a possibilidade de que a cirurgia seja o melhor caminho. (VEJA, 2018, s,p.).

A posiçăo que enuncia na materialidade jornalística parte de saberes especializados, através da remissăo aos estudos desenvolvidos em Havard e apresentados em congressos, para enunciar acerca da necessidade de os adolescentes também realizarem a cirurgia bariátrica ("o tratamento a longo prazo mais eficaz para a perda de peso). Conforme podemos observar, o saber científico, reiterado na notícia pela apresentaçăo do discurso direto de uma médica e pelo discurso indireto do CDC (Centro de Controle e Prevençâo de Doenças dos Estados Unidos, na sigla em inglês), incide sobre um determinado grupo populacional, no caso dos adolescentes obesos, de maneira a administrá-lo e geri-lo. Ao sugerir a bariátrica como uma alternativa mais viável para sanar o problema da obesidade entre esse grupo etário, o saber médico imbui-se de interesses biopolíticos, na medida em que busca garantir a saúde o bem-estar para os adolescentes obesos. 
Esses interesses, de acordo com a reportagem, estâo matizados por dados estatísticos que projetam uma tendência para a continuidade da obesidade na vida adulta de adolescentes ou crianças que já se encontram em tal condiçăo ("uma probabilidade cinco vezes maior de se tornarem adultos com obesidade ou com excesso de peso"). 0 enlace entre os saberes médicos e estatísticos constitui um foco de atuaçáo da biopoltíica de combate à obesidade, uma vez que, consoante Foucault (2007, p. 155), "os processos da vida săo levados em conta por procedimentos de poder e de saber que tentam controlá-los e modificá-los". Para tanto, é sobre o corpo que intervêm essas políticas da vida. É sobre o corpo que pesam os efeitos de uma biopolítica responsável por fazer funcionar um dispositivo de normalizaçâo do corpo obeso, especificamente pela via de um procedimento cirúrgico, tendo em vista que o olhar sobre o obeso o constrói como "um doente social, um indivíduo sem vontade, incômodo e dispendioso" (VIGARELLO, 2012, p. 318).

Além disso, o aspecto numérico, consoante frisa Rose (2013), corporifica-se em projetos de mapeamento que legitima uma tradiçăo de verter em estatística a saúde, a doença e a documentaçấo dos custos em saúde. Os índices acerca do número ainda inexpressivo da realizaçấo da bariátrica na populaçấo de adolescentes asseguram a necessidade de intervir sobre essa parcela do corpo populacional, sob a forma de recomendaçōes e prospecçóes. Essa orientaçăo, de acordo com a materialidade em estudo, deve incidir sobre todos os que estăo diretamente vinculados à promoçấo da saúde, como médicos, enfermeiros e assistentes sociais. Em suma, a reportagem elucida estratégias de natureza biopolítica as quais se encontram atreladas ao discurso da medicina que objetiva o adolescente obeso como um sujeito que precisa ser perscrutado pelo saber clínico cujo incentivo visa intensificar a cirurgia bariátrica como uma alternativa mais eficiente no combate à obesidade.

Já na materialidade a seguir, o sujeito enunciador constrói certas impressóes sobre a cirurgia bariátrica a partir do posicionamento de quem já realizou a gastroplastia - a psicanalista e jornalista Anna Carolina Lementy. Observemos alguns excertos:

5 motivos para afirmar: emagrecer com cirurgia bariátrica năo é fácil

Comigo nunca aconteceu (até agora), mas sei que é extremamente comum ouvir variaçōes da seguinte frase: "mas, com bariátrica, até eu emagreço!". Năo condeno quem pensa assim. Até eu mesma ser operada, via a cirurgia como uma ferramenta que me permitiria fazer com facilidade o que jamais consegui - fechar a boca. Cheguei a dizer, inúmeras vezes, "esta cirurgia será um freio", "será uma barreira física que me impedirá de comer", "vou poder comer tudo, só que pouco, e nunca mais vou engordar".

[...] Voltando à frase que mais cedo ou mais tarde atinge os bariátricos, a de que é fácil emagrecer com cirurgia, acho que só é possível desconstruir esse tipo de pensamento a partir da experiência. As cirurgias bariátricas ou metabólicas têm dois lados, um ótimo e outro verdadeiramente ruim. É preciso abrir măo de parte do estômago e, em alguns casos, mudar a rota do intestino para descobrir.

O que eu descobri neste primeiro mês é que agora tenho uma nova chance de mudar de vida. Náo só de perder peso, o que, evidentemente, acontece, mas de cultivar novos hábitos. Eu perdi 11 quilos desde que operei e já me sinto muito mais disposta. Durmo menos (antes, eu praticamente hibernava), ando mais, muito mais, sem 
perder o fôlego, consigo recusar iguarias que antes repetiria sem dó ou sofreria demais se comesse só uma porçâo. Finalmente, vejo alguns contornos corporais se definindo no espelho. (LEMENTY, 2015, s.p.).

O sujeito que enuncia dota-se de uma autoridade para falar, na medida em que, ao passar pelo procedimento da cirurgia bariátrica, tem legitimidade para produzir verdades sobre essa questăo ("desconstruir esse tipo de pensamento através da experiência"). Assim, o sujeito o faz por meio de uma afirmaçāo categórica "emagrecer com a cirurgia bariátrica nāo é fácil", através da enumeraçâo de algumas razōes que irâo corroborar essa assertiva. Para tanto, a posiçấo sujeito elenca determinados dizeres vindos dos outros ("mas com bariátrica, até eu emagreço") como ditos a si mesmo ("esta cirurgia será um freio", "será uma barreira física que me impedirá de comer"), os quais constituem já-ditos sobre as benesses da cirurgia bariátrica que, de acordo com o posicionamento da materialidade, náo se confirmam na prática. Noutros termos, foi somente quando o sujeito realizou a bariátrica que foi possível descobrir as reais possibilidades ocasionadas pela intervençâo cirúrgica as quais nâo coincidem com as verdades do senso comum, pois, mesmo após a gastroplastia, a luta contra o ganho de peso persiste.

Quando elenca os benefícios da bariátrica para a saúde, além da expressiva perda de gordura, como a retomada da disposiçâo física ("durmo menos), da resistência muscular ("ando mais, muito mais"), a contençăo em consumir alimentos que causam o ganho de peso ("consigo recusar iguarias que antes repetiria sem dó") e as mudanças na forma física ("vejo alguns contornos corporais se definindo no espelho"), o sujeito discursiviza as vantagens advindas do tratamento e reconhece que o esforço em se submeter a essa intervençâo foi válido, de modo a nos mostrar, conforme discute Foucault (2006, p.126), que "dizendo o que se vê o integramos espontaneamente ao saber". Figuram-se, nos dizeres dessa materialidade, os efeitos daquilo que Castiel, Sanz-Valero e VasconcellosSilva (2011) denominam de doença-puniçâo. Os autores analisam a conexăo existente entre medicina e religiăo e que se exibe em interpretaçóes religiosas dos significados da doença. Nesse sentido, os autores frisam que a doença-puniçâo "[...] ocorreria como o resultado de açôes provocadas pelo indivíduo ao transgredir regras e normas desejáveis (religiosas/médicas) de comportamento, seja por omissăo, seja por excesso" (CASTIEL; SANZ-VALERO; VASCONCELLOS-SILVA, 2011, p. 132). Articulando essa reflexăo ao nosso objeto de estudo, acreditamos que o sujeito obeso seria portador de uma doença-puniçăo, pois, ao infringir a norma da saúde compulsória, se constituiria como co-responsável pelos problemas provocados pela sua transgressáo. A bariátrica, nesse caso, representaria a purificaçấo do mal e a possibilidade de uma construçâo de um estilo de vida em paz com o dispositivo de normalizaçăo.

Podemos sustentar que o relato de Lementy enceta mecanismos de regulaçăo do corpo do sujeito obeso, pois demonstra que a bariátrica constitui a possibilidade de objetivar esse corpo na ordem do discurso do bem-estar e da boa forma. A confissâo do sujeito enunciador sugere uma certa transformaçăo de si mediante técnicas de saber-poder responsáveis por garantir a seguridade ao corpo obeso e permitir a sua inserçăo na trama moral vigente. De acordo com Candiotto (2013), o biopoder engendra estratégias que visam a administrar o corpo humano como membro de uma espécie biologicamente constituída. Ainda na perspectiva do autor, essas instâncias de poder assinalam "diferentes processos de subjetivaçâo a partir do embate agonístico entre as forças do querer e as potências da liberdade" (CANDIOTTO, 2013, p.81). Tais processos 
relacionam-se com as agruras, os anseios e as lutas que o sujeito que realiza a bariátrica trava consigo mesmo e com os outros, tendo em vista o espectro da obesidade que sonda esse sujeito, mesmo após a cirurgia. Atemo-nos, portanto, aos modos por meio dos quais o sujeito que enuncia na materialidade analisada exerce um trabalho de transformaçăo de si por meio do regime de verdade em voga.

Esse trabalho fica mais em evidência quando o sujeito lista os motivos que fazem com que o processo de emagrecimento, a despeito da gastroplastia, ser algo lento e complexo. O primeiro motivo diz respeito ao fato de a cirurgia ser congenitamente uma intervençâo arriscada. De acordo com a jornalista: “Como năo tenho religiăo, crença ou mesmo fé em qualquer deus, tive que me lançar ao incerto da vida e esperar a volta da anestesia com saúde" (LEMENTY, 2018, s.p). Prossegue o relato revelando: "Meus últimos pensamentos antes de apagar tinham a ver com "precisava mesmo estar aqui?". Nesse excerto, é possível entrever que as representaçôes sociais em torno de quaisquer procedimentos cirúrgicos entram em cena quando o sujeito resolve se submeter à bariátrica, de maneira a suscitar uma dada reflexáo acerca dos limites para a consecuçăo do corpo saudável. O segundo motivo constitui um corolário do primeiro, na medida em que delata os sacrifícios por que passam o paciente da bariátrica: "Durante 21 dias você năo vai ingerir nada além de líquidos ralos (nem sopinha cremosa pode)" (LEMENTY, 2018, s.p), o que reitera a disposiçâo dos que se submetem a tal terapêutica.

O terceiro motivo recobre as dificuldades enfrentadas nas primeiras refeiçōes: "Você sonhou tanto com esse dia e agora ele está aqui na sua frente. Prepare-se para entalar" (LEMENTY, 2018, s.p). O quarto motivo denota os anseios de engordar mesmo após a cirurgia: "Pessoas que sofrem para emagrecer ou mesmo que năo conseguem emagrecer irăo continuar lidando com esse fantasma mesmo após a cirurgia" (LEMENTY, 2018, s.p). O último motivo frisa que a realizaçâo da bariátrica năo autoriza o consumo desenfreado de todo e qualquer alimento: "[...] pessoas que fizeram cirurgia bariátrica năo poderâo comer besteira com frequência" (LEMENTY, 2018, s.p). O funcionamento discursivo dessa materialidade atesta como os mecanismos de saber-poder intervêm sobre o corpo do sujeito que passou pela terapêutica da cirurgia bariátrica, haja vista que se trata de um corpo a ser constantemente controlado, disciplinado e vigiado, seja antes, durante ou após a gastroplastia. Essa ordem do corpo sólido e visível (FOUCAULT, 2006) dar a ver os diversos tormentos relacionados ao tratamento em estudo, tanto do ponto de vista fisiológico-nutricional, a partir do consumo de alimentos líquidos por um tempo considerável, seja do ponto de vista psicológico-comportamental, pois se pressupóe uma temperança no tocante à alimentaçăo e se intensifica o pavor de engordar novamente.

Concebemos, com base em Vigarello (2012, p.317), que "o discurso sobre a obesidade progressivamente foi tomado pelo autotestemunho, a análise íntima, o relato pessoal". Isso pode ser constatado de maneira parcial na materialidade ora analisada e será mais bem enfatizado nos dizeres a seguir, os quais constituem em depoimentos publicados no site Bariátricos.

Excerto 1: Acho que năo é exagerado dizer que mudou 'tudo' na minha vida. Costumo dizer que os 3 pilares mágicos do pós-cirurgia săo os seguintes:

1)Dieta

2) Prática regular de exercícios físicos 


\section{3) Exames médicos periódicos}

Mudando estes 3 pilares, como eu aceitei o desafio de mudar, você automaticamente mudará de vida. Passei a fazer sempre boas escolhas alimentares, tornando minhas refeiçóes mais funcionais (TROMBONI, 2016, s.p.).

Excerto 2: [...] eu tinha medo de năo andar mais, de me aprisionar de vez aquele corpo, de vegetar diante dos dias, e simplesmente desperdiçar o dom da vida, entre as grades invisíveis da obesidade.

Fazem (sic) um ano e cinco meses apenas, que livrei de meus ombros um peso que a (sic) anos era obrigada a levantar com ele da cama, e hoje ele năo está mais aqui. Posso dizer que tem sido a viagem mais fantástica que poderia realizar, onde (sic) ter de volta a liberdade de locomoçâo, de realizar tarefas que pra (sic) muitos săo banais, como higienizaçăo do próprio corpo, um cruzar de pernas, um ir até a esquina sem precisar está (sic) dentro de um carro, ir a uma loja onde pessoas 'comuns' compram roupas e năo ser olhada como um 'ET', e lá escolher uma roupa e năo um saco qualquer lhe escolher (Sim! A indústria da moda só dispóe de roupas sem cores, cortes, e estilo pra quem está a margem da obesidade), sâo sensaçôes que năo há palavras que descrevam. Nem digo que a vida mudou, e sim que ela surgiu. (ARAÚJO, 2017, s.p.).

Os relatos em primeira pessoa refletem as transformaçóes que o sujeito que realizou a bariátrica tem sofrido. Pode-se observar na composiçáo de tais enunciados uma ênfase na mudança corporal e nas implicaçōes na autoestima e na relaçâo de si para consigo, conforme mostramos em trabalho anterior (XXXX). No excerto 1, o sujeito enunciador admite que sua vida mudou de maneira completa, porquanto passou a adotar um estilo de vida em conformidade com as biopolíticas. A valorizaçâo da saúde, materializada nas dietas, na prática de exercícios físicos e na realizaçăo de exames periódicos, inscreve esse sujeito na lógica de instâncias de poder promotoras de transformaçăo da vida humana (FOUCAULT, 2007). No excerto 2, a posiçăo-sujeito é mais incisiva na narrativa das melhorias resultantes da gastroplastia. A metáfora da viagem de que o sujeito utiliza para descrever a bariátrica ("a viagem mais fantástica que eu poderia realizar") mostra que a cirurgia representa a possibilidade de sair da ordem natural das coisas e de concretizar um desejo até entâo inatingível. O testemunho recai sobremaneira sobre a efetivaçáo de açôes antes impossíveis como se locomover, cuidar do corpo e comprar roupas sem constrangimentos.

Esses relatos póem a nu o fato de o obeso viver em um corpo humilhado (VIGARELLO, 2012) e, para solucionar tal situaçăo, a cirurgia bariátrica aparece como o caminho mais eficaz. Ademais, esses testemunhos metonimicamente assinalam os efeitos do biopoder na construçâo do sujeito na relaçâo com o corpo. Ou seja, o sujeito que se confessa produz uma verdade sobre si e acerca do seu corpo na esteira das modalidades biopolíticas responsáveis por preconizar a preservaçăo da vida e o cuidado de si. A bariátrica denota o ingresso do sujeito na norma que rege as biopolíticas, a partir do momento em que o corpo sai das sombras da doença e adentra nas luzes da vitalidade. Trata-se, acima de tudo, de uma forma de governo, compreendida por Foucault (2008a), como a racionalidade de governar o melhor possível e de gerenciar os corpos e as subjetividades. O sujeito que descreve sua experiência com a bariátrica governa a si mesmo e governo o outro, a quem exerce um poder através do exemplo e da superaçăo. 
Por fim, chegamos às ultimas materialidades discursivas selecionadas para este estudo: dois vídeos de uma campanha da Sociedade Brasileira de Cirurgia Bariátrica e Metabólica (SBCBM). As materialidades audiovisuais possuem trinta e quatro segundos e trinta segundos de duraçấo, respectivamente e apresentam uma narrativa similar. No primeiro vídeo, uma jovem com formas físicas proeminentes entra no que aparentemente seria uma sala de espera onde outras pessoas encontram-se sentadas folheando revistas ou manuseando celulares. O som é uma trilha instrumental que denota medo, apreensăo e suspense. A câmera foca na pose dessas pessoas com as pernas cruzadas e, em seguida, exibe a dificuldade da jovem da campanha em executar semelhante posiçăo. Logo em seguida, o sujeito obeso aparece magro e, finalmente, consegue se igualar aos demais e também cruzar as pernas. No final do vídeo, a jovem sorri e pega uma revista que está num dos assentos da sala de espera. Uma voz em off anuncia: "cirurgia bariátrica feita com qualidade traz qualidade de vida".

Por se tratar de uma campanha de uma organizaçâo médica, convém atentarmos para a formaçáo do que Foucault (2010) denominou de modalidades enunciativas. 0 autor nos fala que, ao enunciar, o sujeito recorre a lugares institucionais para dar legitimidade ao seu dizer. A campanha em estudo, ao ser produzida por uma instituiçâo, recobre-se pelos saberes e poderes que demarcam a atuaçáo dessa entidade. Nesse sentido, a situaçăo criada no vídeo mostra-nos que a jovem obesa se encontra num lugar do anormal, considerando que todos os presentes na sala de espera conseguem cruzar as pernas e ela náo. O efeito quase mágico do emagrecimento no vídeo simboliza que a bariátrica seria a condiçâo peremptória para a normalizaçăo do sujeito obeso e a garantia de sua felicidade. As tecnologias da biopolítica entram em jogo quando refletimos que a populaçăo de obesos constitui o foco da organizaçáo em questăo e o destinatário da campanha. É o corpo dessa fraçăo populacional que se faz necessário gerir, controlar e governar. De acordo com Foucault (2008b, p. 494), a populaçăo é percebida como "o conjunto de seres vivos e coexistentes, que apresentam características biológicas e patológicas específicas".

O segundo vídeo ilustra a seguinte cena: uma jovem obesa entra numa loja de roupas e se depara com os olhares impertinentes e cochichos inoportunos das vendedoras. Logo em seguida, uma das vendedoras imediatamente mostra uma peça de roupas à jovem e a câmera exibe esta última magra e com um sorriso no rosto. A campanha, ao aludir a queixas frequentes de pessoas gordas e obesas quanto à dificuldade em encontrar roupas, discursiviza que a gastroplastia tende a garantir a qualidade de vida, a saúde e a consecuçâo de uma existência feliz. Em suma, nos discursos acerca da cirurgia bariátrica, é possível notar que se tem a bifurcaçăo da identidade do sujeito obeso que compreende o período anterior à cirurgia, a partir de efeitos de exclusăo e de sofrimento, e a fase posterior do procedimento, marcada pela inclusăo do sujeito na ordem da boa forma e na satisfaçăo pessoal.

\section{CONSIDERAÇÕES FINAIS}

Tomando como ancoragem algumas materialidades discursivas que enunciam acerca da cirurgia bariátrica, nosso objetivo neste texto consistiu em investigar o funcionamento de estratégias biopolíticas que procuram assegurar a saúde e o bem-estar 
aos sujeitos com índices elevados de obesidade, tendo em vista o apelo à gastroplastia e toda a preponderância que essa intervençăo cirúrgica alcançou nos últimos tempos. Pensando no funcionamento discursivo dos dispositivos de saber-poder, foi possível constatar determinadas estratégias de cunho biopolítico nos dizeres estudados, na medida em que situam a cirurgia bariátrica no bojo de uma discussăo que aponta para a urgência em garantir a qualidade de vida aos sujeitos obesos, grupo populacional sobre o qual é preciso lançar toda sorte de esforços de gestăo e de governo.

Essas estratégias vinculam-se à natureza das materialidades estudadas, considerada a partir do lugar de onde enunciam e dos seus objetivos. Assim, na reportagem da revista Veja, o foco incide sobre o número inexpressivo de adolescentes que realizam a gastroplastia e, com isso, engendra-se uma defesa de que a bariátrica configura-se como um tratamento válido no combate à obesidade entre os adolescentes. No texto que circulou no site HuffPost Brasil, a fala da jornalista e psicanalista Anna Carolina Lementy constitui um posicionamento discursivo segundo o qual o processo de emagrecimento, mesmo após a realizaçăo da bariátrica, representa uma trajetória dolorosa e desafiadora. Esse posicionamento procura desmistificar determinadas representaçóes para as quais a bariátrica eliminaria a gordura de maneira irreversível. Nos depoimentos contidos no site Bariátricos, flagramos discursos confessionais de sujeitos que já realizaram a cirurgia e a categorizam como sendo a oportunidade de modificar radicalmente a imagem de si e o estilo de vida. Por último, nos vídeos da campanha da SBCBM, entrevemos o emprego de estratégias, na materialidade audiovisual, que mostram a inclusăo e o contentamento dos sujeitos em virtude da cirurgia bariátrica.

Em todas as materialidades examinadas, percebem-se a emergência de técnicas que fabricam os sujeitos em funçăo de modificaçôes corporais. Essas técnicas agenciam a normalizaçăo de corpos que escapam de uma ortopedia moral tributária do corpo magro como sinônimo de saúde e vitalidade e, como corolário, da abjeçáo à gordura e ao corpo obeso, concebidos como o sinal da preguiça, da fraqueza e do fracasso. Noutras palavras, o corpo obeso esquiva-se das tecnologias do biopoder e das biolíticas, dado que denuncia a iminência da doença e o risco da morte. Daí ser premente popularizar técnicas de intervençăo corporal, como a cirurgia bariátrica, que visam a remediar o problema. Seja no perigo do corpo obeso do adolescente, nas verdades sobre o corpo no decorrer do tratamento, nos relatos dos sujeitos que fizeram o procedimento, nos recursos sociotécnicos de campanhas em torno da gastroplastia, erigem-se tecnologias biopolíticas as quais visam controlar e administrar corpos que deverăo ser transformados, com vistas a garantir, governar e prolongar a vida biológica das populaçôes. 


\section{REFERÊNCIAS}

BARROSO, M. F. R. et al. Caracterizaçăo sócio demográfica e clínica de pacientes submetidos à cirurgia bariátrica, Rev. Pesq Saúde, Săo Luís, v. 1, n.2, p.86-90, maio/ago. 2017. Disponível: http://www.periodicoseletronicos.ufma.br/index.php/revistahuufma/article/viewFile/8383/5207. Acesso em: 04 maio 2018.

CANDIOTTO, C. Cuidado de si e dispositivo de segurança: a atualidade da biopolítica. In: CASTELLO-BRANCO, G.; VEIGA-NETO, A. (Orgs.). Foucault: filosofia \& política. Autêntica: Belo Horizonte, 2013. p. 81-96.

CASTIEL, L. ; SANZ-VALERO, J. ; VASCONCELLOS-SILVA, P. R. Das loucuras da razāo ao sexo dos anjos : biopolítica, hiperprevençăo, produtividade científica. Rio de Janeiro: Editora FIOCRUZ, 2011.

COSTA, D. P. Blogs terapêuticos e discursos biopolíticos. In: SOUSA, K. M.; PAIXĀO, H. P. P. Dispositivos de poder/saber em Michel Foucault: biopolítica, corpo e subjetividade. Sáo Paulo: Intermeios, 2015, p.31-42.

DE-MARCHI, J. et al. Cuidados perioperatórios em cirurgia bariátrica no contexto do Projeto ACERTO: realidade e o imaginário de cirurgiōes em um hospital de Cuiabá, Rev. Col. Bras. Cir, Rio de Janeiro, v. 44, n. 3, p. 270-277, 2017. Disponível em: http://www.scielo.br/pdf/rcbc/v44n3/0100-6991-rcbc-44-03-0270.pdf. Acesso em: 03 maio 2018.

DUARTE, A. 2008. Biopolítica e resistência: o legado de Michel Foucault. IN: RAGO, Margareth; VEIGA-NETO, Alfredo (Orgs.). Figuras de Foucault. 2 ed. Belo Horizonte: Autêntica, p.45-56.

FOUCAULT, Michel. História da Sexualidade 1: a vontade de saber. Traduçăo de Maria Thereza da Costa Albuquerque e J. A. Guilhon Albuquerque. Rio de Janeiro: Ediçôes Graal, 1988.

FOUCAULT, Michel. Aula de 17 de março de 1976. In: Em defesa da sociedade: cursos no Collège de France (1975/1976). Săo Paulo: Mantins Fontes, 1999.

FOUCAULT, Michel. História da sexualidade 3: o cuidado de si. Traduçāo de Maria Thereza da Costa Albuquerque. Rio de Janeiro: Ediçōes Gaal, 2005.

FOUCAULT, Michel. O nascimento da clínica. Trad. Roberto Machado. Rio de Janeiro: Forense Universitária, 2006.

FOUCAULT, Michel. Nascimento dabiopolítica: curso dado no Collège de France. Trad. Eduardo Benício. Sāo Paulo: Martins Fontes, 2008a. (Coleçâo trópicos).Segurança, território e populaçâo: curso dado no Collège de France (1977-1978). Trad. Eduardo Brandâo. Sâo Paulo, Martins Fontes, 2008b. 
FOUCAULT, Michel. O sujeito e o poder. In: DREYFUS, Hubert L. e RABINOW, Paul. Michel Foucault: uma trajetória filosófica para além do estruturalismo e da hermenêutica. Rio de Janeiro: Forense Universitária, 2009.

FOUCAULT, Michel. A arqueologia do saber. Trad. Luiz Neves. Rio de Janeiro: Forense Universitária, 2010.

FOUCAULT, Michel. Governamentalidade.In:MACHADO, Roberto (org.). Microfísica do Poder. 26 ed. Sâo Paulo: Graal, 2013a, p. 407-431.

FOUCAULT, Michel. Sobre a história da sexualidade. In: . Microfísica do Poder. 26. ed. Sáo Paulo: Graal, 2013b, p. 363-406.

MARCHESINI, S. D.; ANTUNES, M. C. A percepçăo do corpo em pacientes bariátricos e a experiência do reganho de peso, Interaçôes em Psicologia, Curitiba, v. 21, n.2, p. 127-136, 2017.

ROSE, N. A política da própria vida: biomedicina, poder e subjetividade no século XXI. Traduçấo por Paulo Ferreira Valerio. Sâo Paulo: Paulus, 2013.

SILVA, C.; FARO, A. Significaçôes relacionadas à cirurgia bariátrica: um estudo no pré e pós-operatório, Salud \& Sociedad, Antofagasta, v.6, n.2, p. 156-169, maio/ago. 2015.

VIGARELLO, G. As metamorfoses do gordo: história da obesidade no Ocidente: da Idade Média ao século XX. Trad. Marcus Penchel. Petrópolis, RJ: Cortez, 2012. 